\title{
Horizontal Inequality in Rationing by Waiting
}

\section{Lists}

Gustav Tinghög, David Andersson, Petter Tinghög and Carl H. Lyttkens

The self-archived postprint version of this journal article is available at Linköping University Institutional Repository (DiVA):

http:// urn.kb.se/ resolve?urn=urn:nbn:se:liu:diva-65396

N.B.: When citing this work, cite the original publication.

Tinghög, G., Andersson, D., Tinghög, P., Lyttkens, C. H., (2014), Horizontal Inequality in Rationing by Waiting Lists, International J ournal of Health Services, 44(1), 169-184.

https:// doi.org/ 10.2190/ HS.44.1.j

Original publication available at:

https:// doi.org/ 10.2190/HS.44.1.j

Copyright: SAGE Publications (UK and US)

http:// www.uk.sagepub.com/home.nav 


\section{Horizontal Inequality in Rationing by Waiting Lists}

Gustav Tinghög ${ }^{1,2}$, David Andersson ${ }^{1}$, Petter Tinghög ${ }^{3,4}$, Carl Hampus Lyttkens ${ }^{5}$

Cite this article as:

Tinghög, G., Andersson, D., Tinghög, P., Lyttkens, C. H. (2014). Horizontal

Inequality in Rationing by Waiting Lists. International Journal of Health Services, 44(1), 169- 184.https://doi.org/10.2190/HS.44.1.j

${ }^{1}$ Center for Medical Technology Assessment, Department of Medical and Health Sciences, Linköping University, Linköping, Sweden

${ }^{2}$ The National Center for Priority Setting in Health Care, Linköping University, Linköping, Sweden

${ }^{3}$ Department of Bioscience and Nutrition, Karolinska Institute, Stockholm, Sweden ${ }^{4}$ Department of Neuroradiology, Karolinska University Hospital, Stockholm, Sweden ${ }^{5}$ Department of Economics, School of Economics and Management, Lund University, Lund, Sweden

\section{Corresponding Author:}

Gustav Tinghög

Department of Medical and Health Sciences

Linköping University

SE-581 83 Linköping

Sweden

Email: gustav.tinghog@liu.se

Phone: +46 13221751

Fax: +4613224995 


\section{ABSTRACT}

Objective: To investigate the existence of horizontal inequality in access to care for six categories of elective surgery in a publicly funded system, when care is rationed through waiting lists.

Data Source: Administrative waiting-time data on all elective surgeries ( $\mathrm{N}=4634)$ performed in Östergötland, Sweden during 2007 were linked to national registers containing variables on socioeconomic indicators.

Study design: By using multiple regression, we tested five hypotheses reflecting that more resourceful groups receive priority when rationing by waiting lists.

Principal findings: Low disposable household income predicted longer waiting times for orthopedic surgery $(27 \%, \mathrm{p}<0.01)$ and general surgery $(34 \%, \mathrm{p}<0.05)$. However, no significant differences on the basis of ethnicity and gender were detected. A particularly noteworthy finding was that disposable household income appeared to be an increasingly influential factor when the waiting times were longer.

Conclusions: Our findings reveal horizontal inequalities in access to elective surgeries, but only to a limited extent. Whether this is good or bad depends on one's moral inclination. From a policymaker's perspective it is nevertheless important to recognize that horizontal inequalities arise even though care is not rationed through ability to pay.

Keywords: rationing, waiting list, horizontal equity, elective surgery, Sweden 


\section{INTRODUCTION}

All healthcare systems ration care in one way or another. Rationing aims at bridging the gap between demand and available resources by limiting the possibilities to fully meet the need for health care. The method for conducting rationing can take different forms. When care is rationed by price, demand is restrained by the monetary price, which the patient faces at the point of demand. According to standard economic models price is increased until demand and supply converge at a market-clearing price. In public systems where care often is free or priced well below market-clearing level, demand and supply must be reconciled through other rationing devices.

Rationing by price raise delicate normative issues related to equality in general and different socioeconomic groups' equal access to health services in particular. Within publicly funded health-care systems distributional issues related to some notion of equality are often core concerns $^{1}$ (van Doorslaer et al., 1993, Hurst, 2002). The notion of horizontal equity is typically interpreted to mean that: people in equal need are to be treated equally, irrespective of personal characteristics such as age, gender, income, and ethnicity (Wagstaff and van Doorslaer, 2000). Adherence to the principle of horizontal equity is difficult to maintain when care is rationed by price. Therefore, public funded systems commonly rely on waiting lists as a mechanism to limit availability, while still trying to maintain that persons in equal need are treated equally. However, since rationing by waiting lists is most often done implicitly, there are reasons to suspect the presence of systematic socioeconomic differences in waiting times for patients with equal need, i.e. similar medical condition. This study investigates the existence of horizontal inequality in waiting times for six types of elective surgery in the Swedish healthcare system.

Waiting lists are conceptually related to waiting lines ${ }^{2}$. When care is rationed through waiting lines, individuals are required to physically remain in a queue until being admitted to care. The time during which individuals are restrained from performing other activities constitutes an opportunity cost, making individuals less prone to seek care. Waiting lists, on the other hand,

\footnotetext{
${ }^{1}$ We will in this paper refer to equality as a descriptive notion and equity as a normative notion. Much of the existing literature has failed to recognize this important difference. For a more thorough discussion with regards to the relationship between equality and equity see (\#reference deleted\#)

${ }^{2}$ Both are dynamic rationing tools in the sense that the number of patients waiting at a given moment in time will be dependent on the expected waiting time.
} 
do not require individuals to physically remain in a queue while waiting. Instead waiting lists operate as a rationing mechanism mainly because the value of future treatments declines the longer the individual has to wait; this produces convergence between supply and demand (Lindsay and Feigenbaum, 1984, Martin and Smith, 1999). To illustrate the different rationing mechanisms at play, one can think of the time spent in line at a fast food restaurant compared to the extra waiting time associated with ordering take-out. While standing in line at the fast food restaurant prohibits persons from doing most other activities, ordering take-out allows one to participate in other activities of their choice.

It is important to acknowledge that the declining value of future treatment is not merely an economic discounting device. Being on a waiting list also involves increased burdens as a result of the disutility associated with remaining on the waiting list (Propper, 1995). Returning to the example of the fast food restaurant; while the person who orders take-out is able to participate in other activities, they are also likely to experience increased hunger as a result of the extra waiting time. This study focuses on inequalities in access related to rationing by waiting lists.

\subsection{Previous research on waiting times in public healthcare systems}

When investigating inequalities in access to health services it is also important to recognize that waiting times constitute only a small, albeit important, part of the wider concept of access to health services. Much of the empirical literature on horizontal inequality and access to health care has focused on other components of access, such as the utilization, provision, and delivery of healthcare services (van Doorslaer et al., 2000, d'Uva et al., 2009, Wagstaff and Vandoorslaer, 1992). Horizontal inequality as regards to waiting times in publicly funded systems is, by comparison, a less systematically explored area. A vast, but disparate, body of literature exists concerning the association between various categorizations of socioeconomic status and waiting time for specific patient groups or treatments (Pell et al., 2000, Yong et al., 2004, Fitzpatrick et al., 2004, Milner et al., 2004, Hacker and Stanistreet, 2004, Pettinger, 1999, Shortt and Shaw, 2003). Only a few have investigated such associations within the context of the Nordic healthcare systems (Hojmark Sorensen et al., 2009, Carlsen and Kaarboe, 2010, Lofvendahl et al., 2005, Arnesen et al., 2002). Of these, some have confirmed the existence of a link between lower socioeconomic status and increased waiting time within specific treatment domains (Hojmark Sorensen et al., 2009, Carlsen and Kaarboe, 2010), while others found no such link (Arnesen et al., 2002, Lofvendahl et al., 2005). Moreover, all previous studies have 
varied extensively in terms of setting, methodology, and objectives, making it difficult to draw general conclusions from previous studies about the association between waiting time and socioeconomic status.

In terms of setting and objective, the study by Siciliani and Verzulli (2009) is the one most similar to this study. Hence, their results are also the most relevant for comparison purposes. Their study uses data from the Survey of Health, Ageing, and Retirement in Europe (SHARE) when investigating how socioeconomic status among elderly Europeans influences waiting times (at a given level of need) for specialist consultation and non-emergent surgery. According to their findings, patients with higher levels of education experienced shorter waiting times for non-emergent surgery in Sweden. Their results also showed that an increase in income by 10000 Euros (EUR) decreased waiting time by 3\% (but this association failed to reach the significance level). Seemingly contradictory, they also found that an increase in income of EUR 10000 increased waits for specialist consultation by 11\%. Siciliani and Verzullis' findings were based on a self-reported data from a limited sample population $(n=247)$ with a high nonresponse rate. Hence, it will be interesting to see if their findings can be replicated within a larger and more reliable sample.

\subsection{Why do we expect horizontal inequalities in waiting times?}

At least three types of reason can be given for suspecting systematic socioeconomic differences in waiting times for patients with equal need. From the perspective of economic efficiency it would seem reasonable prioritize individuals that are more productive. Hence, one could argue that it is more efficient to prioritize individuals who currently hold a job. Further, if assuming that income is related to productivity, it would be more efficient to prioritize high-income individuals. One could also argue that prioritizing younger individuals is more efficient since this would most likely maximize the number of healthy life-years gained. Although rationales related to productivity and 'ageism' is explicitly discouraged at the macro level within the Swedish healthcare system, it does not seem far-fetched that it might play a role in practice when rationing care at the patient level.

The second type of reason is that less resourceful groups are less able to successfully communicate and express their needs, which is an empirically well-established fact (e.g Brewer, 2002). The occurrence of this phenomenon may, however, be understood as a result of several 
non-mutually exclusive factors. One possible explanatory factor is that the working of the lists has been shaped largely by the most advantaged segments of the community, making the lists (either consciously or unconsciously) better suited to accommodate the needs of their peers. This type of explanation may also be advocated in relation to the hypotheses that women and patients of foreign origin experience longer waiting times. A second explanation, to the above describe phenomenon, may be that resourceful groups are more knowledgeable about how the system works, or can at least more effectively acquire such knowledge. This, in theory, would make them better equipped to 'manipulate' the system, e.g. by arguing in ways that strike a chord with personnel that can influence one's time spent on the waiting list.

Finally, the psychological literature establishes that individuals generally tend to have an unconscious (implicit) in-group bias, which makes them more aversive toward groups dissimilar to one's own group (Olsson et al., 2005). As an example, psychological testing of physicians has indicated that unconscious biases may contribute to racial/ethnic disparities in setting healthcare priorities (Green et al., 2007). Although this type of reason is not always easily distinguished in practice from the former reason, it puts a more direct focus on the behaviors of the actors involved in decision making at the patient level.

Given the background described above, this study aims to investigate whether horizontal inequalities exist in waiting times for six types of elective surgeries in the Swedish healthcare system. To achieve this aim we set out to test five hypotheses that more resourceful groups receive priority when rationing is done through waiting lists:

Male patients receive priority over women

Younger patients receive priority over older patients

Patients with higher incomes receive priority over patients with lower incomes

Patients of Swedish origin receive priority over patients of foreign origin

Patients currently active in the workforce receive priority over patients currently inactive.

\section{METHODS \& MATERIALS}

\subsection{Study setting}


Patients in Sweden are assigned to waiting lists as follows: Patients with non-acute conditions first consult their general practitioner, who will refer them to a specialist if needed. In some cases the patient can visit the specialist directly for medical assessment. If patients are considered to require surgery, they will be placed on a waiting list. When investigating inequalities regarding waiting lists there are two main stages where discrimination can occur. First, general practitioner or/and referral specialists might have different standards for different socioeconomic groups which might lead to unequal opportunities to get on the waiting list. Secondly, patients might be treated unequally once they have been placed on the waiting list. This study focuses on this second stage.

In large part the Swedish system is publicly managed, with 21 county councils owning and operating most healthcare facilities. Each county council has a defined geographical catchment area. Patients are restrained from seeking non-acute care outside their own county councils. Although county councils are formally self-governed, Sweden has a long tradition of promoting egalitarian social justice and reducing differences across county councils (Gerdtham and Sundberg, 1998, Anell, 2005). This is highlighted further in the Swedish Health and Medical Services Act (1982), which declares that the objective of the Swedish healthcare system is to promote "good health on equal terms".

In 1992 a maximum waiting time guarantee for 12 elective procedures ${ }^{3}$ was introduced to reduce geographic variations in Sweden. According to this guarantee, patients waiting for surgical procedures should wait no longer than 90 days from referral to surgery, unless an agreement is reached between the patient and the doctor. If the county council fails to meet this requirement the patient has the right to seek surgery in another county council, or at a private clinic, at the expense of the home county council (Hanning, 1996).

Östergötland County Council, from which the administrative waiting time data used in this study was retrieved, is located in the southeastern part of Sweden and has 420000 inhabitants. Three hospitals are located in the catchment area. Most publicly funded elective procedures are performed at these public hospitals, although one private clinic also performs some elective procedures that are publicly funded. Since we were unable to retrieve reliable waiting time data

\footnotetext{
${ }^{3}$ Additional elective procedures have been added since 1992.
} 
from this private clinic we have excluded elective procedures where the private clinic preformed any share of the services.

The catchment area of Östergötland County Council has an age and sex distribution similar to the national distribution (Statistics Sweden, 2010a), and 19.2\% of the inhabitants have higher education (the national average is 18.0\%) (Statistics Sweden, 2010b). Comparing nationwide waiting times for the operation codes included in this study, Östergötland's pattern is similar to the nationwide averages. In Östergötland, 70\% of elective procedures reported in 2007 were performed within the limit of the waiting time guarantee, compared to $73 \%$ for Sweden in total ${ }^{4}$.

\subsection{Study design}

This was a retrospective study in the sense that the lengths of the waiting times were calculated for all patients who received an elective surgery in 2007. This implies that patients who remained on the list or exited the list for reasons other than operation is not included in the data set. Data on waiting time for elective procedures were obtained from the administrative healthcare register in the county of Östergötland, Sweden. The elective procedures were based on the ICD-10 codes used to classify non-acute surgical procedures. In total, 24 non-acute surgical procedures were included. We aggregated these 24 elective procedures into six surgical categories; vascular, orthopedic, gynecology, urology, ophthalmology, and general surgery. In this paper, the 24 non-acute surgical procedures will be referred to as elective procedures while the six categories will be referred to as specialties. The full data set included 4634 patients living within boundaries of the county and treated between January 1, 2007 and December 31, 2007. Patients below 18 years of age and those waiting for a second and presumably related elective surgery were excluded from the data set.

Our dependent variable, waiting time, was defined as the number of days between referral and surgery. The independent variables age, gender, disposable income, ethnicity, and workforce activity were retrieved from Statistics Sweden (SCB) and merged with individual data on waiting time. The income concept used in this study was disposable household income per

\footnotetext{
${ }^{4}$ Data comparing waiting times between different county councils can be retrieved from the publicly available database at http://www.vantetider.se. This database is updated and maintained by the Swedish Association of Local Authorities and Regions (a governmental agency) to monitor and minimize differences in waiting times between county councils.
} 
equivalent adult during 2007. Disposable household income equals the sum of net income in a household divided by the number of people in the household, which is adjusted according to an equivalent scale ${ }^{5}$. Income data are highly reliable since they have been linked to national income tax statistics. Subjects were categorized into three groups using income quartile limits to identify the lowest and highest income groups. In categorizing the level of disposable income for patients above 65 years of age and retired, we used separate quartile limits than for patients of working age. This was done because retired individuals' current income could be misleading as an indicator of socioeconomic status when compared to that of working individuals. The foreign origin variable was defined as patients whose parents were both born outside Sweden. Workforce activity was used as a dichotomized variable, where individuals in retirement, early retirement, unemployment, and education were defined as being non-active in the workforce.

\subsection{Data analysis}

We used multiple linear regression models to investigate the associations between waiting times and our predictors. Although our dependent variable, waiting time (days), was found normally distributed at $\alpha<0.05$ using a Shapiro-Wilk test, we chose to transform the variable to the logarithmic scale. This was done to enable presentation of relative differences between the groups with greater precision and thwart potential outliers from disturbing the analysis conducted for smaller groups of patients (Kirkwood and Sterne, 2003). A multiple regression model was run separately for the six specialties under investigation. To adjust for differences in urgency or severity between elective procedures we entered elective procedures (ICD-10 codes) as covariates into the regression models. Finally, to validate the results from the regression analyses, all two-way interactions were tested. All non-significant interactions at $(\alpha<0.05)$ were removed and the analyses were re-run. Interactions that remained statistically significant were then carefully examined and interpreted.

\section{RESULTS}

The study included 4636 completed waiting-time episodes, and 59\% of the patients were women (Table I). Ophthalmology and orthopedics constituted the two largest surgical

\footnotetext{
${ }^{5}$ The equivalent scale used is: one adult $=1$; two adults $=1.51$; additional adult $=0.60$; first child aged $0-19$ years $=0.52 ;$ and second and following children $=0.42$.
} 
specialties and contributed with $39 \%$ and $21 \%$ of the stock of patients respectively. The average proportion of patients currently not active in the workforce was $71 \%$. Ophthalmology was the surgical specialty with the highest mean age (74.7 years). Consequently, ophthalmology also had the highest proportion of patients categorized as having no workforce activity (88\%). Disposable household income was highest among patients in urology and lowest among patients in gynecology.

Table I Sample characteristics

\begin{tabular}{lcccccc}
\hline & $\mathrm{n}(\%)$ & Age & $\begin{array}{c}\text { Mean } \\
\text { disposable } \\
\left.\text { Income( } €^{*}\right)\end{array}$ & $\begin{array}{c}\text { Proportion } \\
\text { women }\end{array}$ & $\begin{array}{c}\text { Proportion of } \\
\text { foreign origin }\end{array}$ & $\begin{array}{c}\text { Proportion } \\
\text { out of work } \\
\text { force }\end{array}$ \\
\hline Vascular $^{1}$ & $417(9.0)$ & 66,9 & 19172 & 0.30 & 0.13 & 0.71 \\
Orthopedic $^{2}$ & $990(21.4)$ & 60.5 & 18762 & 0.54 & 0.09 & 0.68 \\
Gynecology $^{3}$ & $357(7.7)$ & 58.2 & 17171 & 1.00 & 0.10 & 0.56 \\
Urology $^{4}$ & $204(4.4)$ & 69.9 & 23226 & 0.00 & 0.07 & 0.77 \\
Ophthalmology $^{5}$ & $1792(38.7)$ & 74.7 & 17322 & 0.62 & 0.10 & 0.88 \\
General Surgery $^{6}$ & $874(18.9)$ & 53.8 & 17668 & 0.66 & 0.16 & 0.46 \\
\hline TOTAL & 4634 & 65.5 & 18112 & 0.59 & 0.11 & 0.71 \\
\hline
\end{tabular}

* 1 Euro was calculated as 9.25 SEK according to the annual average exchange rate for 2007.

1) Cardiac valve replacement surgery (211) Coronary artery bypass grafting (206). 2) Carpal tunnel release surgery (342) Hip replacement (269) Knee replacement (230) Synovitis (177) Slipped disc surgery (57) Needle aponeurotomy for dupuytren's contracture (80) Shoulder instability surgery (27) Anterior cruciate ligament surgery (69) Subacromial (27) Spondylolisthesis (8) Rheumatoid arthritis surgery (21) Thumb arthritis (25). 3) Uterine prolapse (195), Operation for incontinence (87) Hysterectomy on benign indications (75). 4). Benign prostatic hyperplasia (188) Scrotal hernia surgery (16). 5) Cataract surgery (1760) Strabismus surgery (18) Operation of lacrimal canal (14) .6) Anal surgery (182) Cholecystectomy (165) Thyroid surgery (60) Varicose veins (77) Scar hernia (48)

Table II shows mean waiting times for the six surgical specialties by demographics. On average, 100 days were spent on the waiting lists. The means ranged from 150 days in orthopedics to 37 days in gynecology.

Table II Mean waiting times (in days) ${ }^{\dagger}$

\begin{tabular}{|c|c|c|c|c|c|c|c|c|c|}
\hline & & \multirow[b]{2}{*}{$\mathrm{n}$} & \multirow[b]{2}{*}{$\%(n=4634)$} & \multicolumn{6}{|c|}{ Mean waiting time (days) } \\
\hline & & & & Vascular & Orthopedic & Gynecology & Urology & Ophthalmology & General Surgery \\
\hline \multicolumn{10}{|l|}{ Gender } \\
\hline & Women & 2717 & 58.6 & 78.7 & 140.7 & 37.2 & & 77.8 & 132.3 \\
\hline & Men & 1917 & 41.4 & 61.8 & 161.3 & & 103.9 & 78.4 & 123.9 \\
\hline \multicolumn{10}{|c|}{ Age group } \\
\hline & $18-39$ & 351 & 7.6 & 87.2 & 121.4 & 42.5 & 76.3 & 75.2 & 123.2 \\
\hline & $40-69$ & 2108 & 45.5 & 64.8 & 152.1 & 36.5 & 91.3 & 71.4 & 133.4 \\
\hline & $70-$ & 2175 & 46.9 & 68.4 & 158.9 & 38.9 & 115.2 & 80.3 & 119.2 \\
\hline \multicolumn{10}{|c|}{ Income group } \\
\hline & Lowest & 1164 & 25.1 & 75.7 & 150.6 & 33.2 & 122.5 & 79.4 & 139.2 \\
\hline & Middle & 2315 & 50.0 & 63.2 & 153.9 & 38.4 & 102.9 & 78.5 & 125.6 \\
\hline & Highest & 1155 & 24.9 & 67.7 & 143.2 & 40.5 & 100.6 & 75.5 & 125.2 \\
\hline \multicolumn{10}{|c|}{ Ethnicity } \\
\hline & Foreign & 508 & 11.0 & 75.1 & 152.3 & 25.7 & 112.5 & 81.1 & 132.3 \\
\hline & Swedish & 4126 & 89.0 & 65.7 & 149.9 & 38.6 & 103.2 & 77.7 & 128.9 \\
\hline \multicolumn{10}{|c|}{ Workforce activity } \\
\hline & No & 3312 & 71.5 & 69.3 & 156.5 & 36.8 & 109.9 & 79.7 & 128.9 \\
\hline & Yes & 1322 & 28.5 & 60.9 & 136.9 & 37.8 & 83.6 & 65.4 & 129.9 \\
\hline TOTAL & & 4634 & 100.0 & 66.9 & 150.1 & 37.2 & 103.9 & 78.0 & 129.4 \\
\hline
\end{tabular}

Table III presents the results of the multiple regression models. Concerning orthopedic surgery, it was found that men waited $18 \%(\mathrm{p}<0.01)$ longer than women. This pattern was, however, not found in other surgical specialties. 
Table III further shows that age predicted waiting time in orthopedics ( $<<0.01)$, ophthalmology $(\mathrm{p}<0.05)$, and general surgery $(\mathrm{p}<0.05)$. However, the direction of the associations differed to some extent among the surgical specialties. In ophthalmology, we found a clear trend that older patients waited longer. In orthopedics and general surgery we found a bell-shaped tendency, i.e. patients between the ages of 40 and 69 years stayed on the waiting list longer in comparison to younger and older patient groups.

Lower disposable household income was found to predict longer waiting times in orthopedics $(\mathrm{p}<0.05)$ and general surgery $(\mathrm{p}<0.05)$, but not in the surgical specialties vascular, gynecology, urology and ophthalmology. In orthopedics, the lowest income group waited on average $28 \%$ $(\mathrm{p}<0.01)$ longer than the highest income group, while low-income patients in general surgery waited on average $34 \%(p<0.05)$, longer compared to individuals in the highest income group.

Ethnicity was associated with waiting time in the case of gynecology, where waiting time for patients of foreign origin was on average $40 \%(\mathrm{p}<0.01)$ shorter than for patients of Swedish origin. The interaction analysis revealed that this difference could be mostly ascribed to differences between patients who are active in the workforce. Hence, this association is only true for patients of foreign origin who are currently active in the workforce. In all other fields of surgery we found a contrasting but non-significant trend that patients of foreign origin waited longer than patients of Swedish origin.

When examining workforce activity as a potential predictor, we found that patients not active in the workforce experienced 29\% $(\mathrm{p}<0.01)$ longer waiting times in ophthalmology. Otherwise no significant associations between workforce activity and waiting time were detected.

Insert table III 


\section{DISCUSSION}

In many OECD countries, societal preferences for solidarity have made rationing by ability to pay an unviable policy option. Limiting access to care through waiting lists has therefore become a widely used rationing tool. Even though equity of access is a central theme in the health services literature, few studies have systematically investigated how rationing through waiting lists violates the principle of horizontal equity. This study provides a systematic analysis of socioeconomic-related inequalities when care is rationed through waiting lists in the Swedish healthcare system.

\subsection{Main findings}

We found some support for the assertion that horizontal inequality occurs when rationing elective surgeries though waiting lists. This picture, however, is not clear-cut, as inequality is not present in all surgical specialties. In vascular and urologic surgery we found no evidence of horizontal inequalities. Concerning gynecology, the results contradicted the stipulated hypothesis, i.e. that more resourceful groups receive priority when rationing by waiting lists. In the specialties of orthopedics, ophthalmology, and general surgery the data supported the presence of horizontal inequalities. Particularly noteworthy in this respect is that lower household income predicted longer waits in both orthopedics and general surgery. These findings are in line with the results presented by Siciliani and Verzulli (2009).

In connection with the finding that low income predicted longer waiting times in orthopedics and general surgery, it is worth noting that these were also the surgical specialties where patients in general experienced the longest waiting times. This may suggest that income becomes an increasingly influential factor as waiting time becomes longer. Alternatively, it could suggest the existence of a potential threshold effect, where disutility associated with waiting is negligible as long as the waiting time does not exceed a certain length. This may be explained by the existence of an initial 'adjustment period' allowing individuals to mentally prepare and make necessary practical arrangements. But in cases where time on the waiting list exceeds this threshold, the disutility associated with continued discomfort and anxiety take over, making individuals increasingly active in trying to gain priority, and thereby favoring more resourceful groups. 
Following this line of reasoning, the existence of an 'adjustment period' could explain why we mainly find horizontal inequalities in accordance with our hypotheses in the specialties with relatively long waiting times. Further studies need to investigate the existence of such a threshold effect and whether the disutility associated with being on a waiting list increases at a hyperbolic or constant rate over time. However, the credibility of the argumentation above could possibly be attributed to differences in levels of urgency and/or severity between the underlying medical conditions related to the investigated surgical specialties. Still, all procedures included in the study were part of a national initiative to harmonize waiting times, indicating that levels of urgency and severity of the related medical conditions are fairly equal.

This study did not confirm our hypotheses concerning ethnicity and gender. Hence, men and patients of Swedish origin did not appear to receive priority. Our finding of no gender inequality contradicts recent findings by Carlsen and Kaarboe (2010), who found that male patients are overrepresented among non-acute Norwegian patients categorized as high-priority cases. This discrepancy may suggest a difference between the Norwegian and the Swedish healthcare systems concerning gender inequality. Another, and probably more likely, explanation for the contradictory results is that Carlsen and Kaarboe (2010) focus on patients who are given the right to treatment versus patients who are declined the right to treatment, as determined by the referring physician. Our study, on the other hand, focuses solely on differences among patients who have already been referred to a specific elective procedure. Hence, female patients may have been discriminated before even getting on the waiting list, but not once they have been placed on the waiting list. This may also explain why the stated hypothesis regarding ethnicity could not be confirmed.

\subsection{Strengths and limitations}

This study has several advantages compared to earlier studies focusing on equity and waiting times. First, Sweden has a long tradition of collecting high-quality data on diseases and healthcare utilization (Rosen, 2002). By using the civic person identification number, we could link waiting-time data from an administrative database to socioeconomic registers. In contrast to earlier studies, this study does not rely on self-reported data or broad, unspecific categories of socioeconomic status. Second, the data in this study allows for comparisons between surgical specialties. Since the data included surgical indications, adjustments concerning elective procedures within surgical specialties could be made. These advantages, we believe, make this 
dataset unique allowing us to investigate waiting lists as a rationing tool in a more detailed way than previously done.

Regarding limitations, first it should be noted that disposable household income is not a flawless indicator of socioeconomic status. Elderly patients might not currently have very high disposable incomes, but could potentially have accumulated wealth during earlier stages in life. This makes current disposable household income potentially misleading as a socioeconomic indicator. Unfortunately, neither accumulated wealth nor educational levels are available as socioeconomic indicators for elderly individuals in Sweden. Nevertheless, there is good reason to assume that the disposable income of retired persons correlates with their disposable income during working age. Since we used separate quartile limits for disposable income of retired patients above 65 years of age we believe that we have captured socioeconomic differences among elderly individuals fairly accurately.

Second, studies of waiting lists as a rationing tool should, in principle, also examine all potential entrants to the waiting list and their responses to expected waiting times. Such data were however not available. This limitation has most likely decreased the socioeconomic differences detected in this study.

Third, the study is based on a retrospective approach in that it only includes individuals who have received an operation. This approach fails to take account of the fact that some individuals might have exited the waiting lists prior to the execution of the awaited procedure. Reasons for exiting could be voluntary or involuntary. A voluntary reason could be that patients adapt to their medical condition and choose to give up their place on the waiting list, or the patient might choose to pay out-of-pocket for privately funded care to gain quicker access. Here, we need to point out that patients who pay out-of-pocket for a procedure covered by public health insurance are extremely rare in Sweden. Death before being admitted to care is the predominant involuntary reason for exiting a waiting list. As there are no obvious reasons to suspect an association between exiting a waiting list and the patients' socioeconomic characteristics, our results would probably not be substantially affected.

Finally, this study is based on waiting-time data from Östergötland County Council, which has a defined geographic catchment area covering less than $5 \%$ of the Swedish population. Despite 
several national initiatives to harmonize clinical practice and waiting times across different county councils, some regional differences within the Swedish context cannot be ruled out.

\subsection{Final remarks}

It is important to acknowledge that the mere association between socioeconomic factors and horizontal inequalities in waiting times cannot alone support judgments about injustice. Economists and philosophers have offered a wide array of justifications for inequality in access on grounds of efficiency and social justice. However, before approaching the delicate normative question concerning which inequalities should be deemed unfair, it is necessary to address the descriptive question concerning which horizontal inequalities actually exist.

This study documents that access is unequal when care is rationed by waiting lists, but only to a limited extent. Whether this is good or bad news depends on your worldview, i.e. your expectations on the functioning of public health care and your normative view of how it should function. From a policymaker's perspective it is important to recognize that horizontal inequalities arise even though care is not rationed through ability to pay. Consequently, horizontal equality in waiting times cannot be assumed in publicly funded healthcare systems unless they are closely monitored and openly discussed. Although our findings are contextspecific to some extent, they are relevant for decision makers in other countries that, like Sweden, rely heavily on waiting lists as a mechanism to ration care.

\section{REFERENCES}

Anell, A. (2005) Swedish healthcare under pressure. Health Economics, 14, S237-S254.

Arnesen, K. E., Erikssen, J. \& Stavem, K. (2002) Gender and socioeconomic status as determinants of waiting time for inpatient surgery in a system with implicit queue management. Health Policy, 62, 329-41.

Brewer, M. B. (2002) The Psychology of Prejudice: Ingroup Love and Outgroup Hate? Journal of Social Issues 55, 429-444.

Carlsen, F. \& Kaarboe, O. M. (2010) Norwegian priority guidelines: estimating the distributional implications across age, gender and SES. Health Policy, 95, 264-70. 
D'uva, T. B., Jones, A. M. \& Van Doorslaer, E. (2009) Measurement of horizontal inequity in health care utilization using European panel data. Journal of Health Economics, 28, 280-289.

Fitzpatrick, R., Norquist, J. M., Reeves, B. C., Morris, R. W., Murray, D. W. \& Gregg, P. J. (2004) Equity and need when waiting for total hip replacement surgery. Journal of Evaluation in Clinical Practice, 10, 3-9.

Swedish Health and Medical Services Act. (1982) in Svensk Författningssamling, SFS Stockholm.

Gerdtham, U. G. \& Sundberg, G. (1998) Equity in the delivery of health care in Sweden. Scandinavian Journal of Social Medicine, 26, 259-264.

Green, A. R., Carney, D. R., Pallin, D. J., Ngo, L. H., Raymond, K. L., Iezzoni, L. I. \& Banaji, M. R. (2007) Implicit Bias among Physicians and its Prediction of Thrombolysis Decisions for Black and White Patients Journal of General Internal Medicine 22, 1231-1238.

Hacker, J. \& Stanistreet, D. (2004) Equity in waiting times for two surgical specialties: a case study at a hospital in the North West of England. Journal of Public Health, 26, 56-60.

Hanning, M. (1996) Maximum waiting-time guarantee--an attempt to reduce waiting lists in Sweden. Health Policy, 36, 17-35.

Hojmark Sorensen, H. T., Olsen, K. \& Vedsted, P. (2009) Association Between General Practice Referral Rates and Patiens' Socioeconomic Status and Access to Specialised Health Care: A Population-based Nationwide Study. Health Policy, 92, 180-186.

Hurst, J. W. (2002) Performance measurement and improvement in OECD health systems: overview of issues and challanges. IN OECD (Ed.) Measuring up: improving health systems performance in OECD countries. Paris, OECD.

Kirkwood, B., Sterne, J. (2003) Essential Medical Statistics (Second ed). Blackwell Oxford. Lindsay, C. M. \& Feigenbaum, B. (1984) Rationing by waiting lists. American Economic Review, 74, 404-17.

Lofvendahl, S., Eckerlund, I., Hansagi, H., Malmqvist, B., Resch, S. \& Hanning, M. (2005) Waiting for orthopaedic surgery: factors associated with waiting times and patients' opinion. International Journal for Quality in Health Care, 17, 133-40.

Martin, S. \& Smith, P. (1999) Rationing by waiting lists: an empirical investigation. Journal of Public Economics, 71, 141-164. 
Milner, P. C., Payne, J. N., Stanfield, R. C., Lewis, P. A., Jennison, C. \& Saul, C. (2004) Inequalities in accessing hip joint replacement for people in need. European Journal of Public Health, 14, 58-62.

Olsson, A., Ebert, J. P., Banaji, M. R. \& Phelps, E. A. (2005) The role of social groups in the persistence of learned fear. Science, 309, 785-7.

Pell, J. P., Pell, A. C., Norrie, J., Ford, I. \& Cobbe, S. M. (2000) Effect of socioeconomic deprivation on waiting time for cardiac surgery: retrospective cohort study. British Medical Journal, 320, 15-8.

Pettinger, N. (1999) Waiting lists. Richly deserving. Health Serv J, 109, 20-1.

Propper, C. (1995) The Disutility of Time Spent on the United Kingdom's National Health Service Waiting Lists The Journal of Human Resources, 30, 677-700.

Rosen, M. (2002) National Health Data Registers: a Nordic heritage to public health. Scandinavian Journal of Public Health, 30, 81-5.

Shortt, S. E. \& Shaw, R. A. (2003) Equity in Canadian health care: does socioeconomic status affect waiting times for elective surgery? Canadian Medical Association Journal, 168, 413-6.

Siciliani, L. \& Verzulli, R. (2009) Waiting times and socioeconomic status among elderly Europeans: evidence from SHARE. Health Economics, 18, 1295-306.

Statistics Sweden. (2010a) Folkmängden efter län, civilstånd och kön. År 1968-2009. Available from www.scb.se/Pages/ProductTables___25795.aspx, accessed 12 May 2010

Statistics Sweden. (2010b) Befolkning 16-74 år efter Kommun, Utbildningsnivå och Kön. År 1985-2009. Available from www.ssd.scb.se/databaser/makro/Produkt.asp?produktid=UF0506, accessed 14 May 2010

\#Reference deleted\#

Wagstaff, A. \& Van Doorslaer, E. (2000) Equity in health care finance and delivery. IN Culyer, A. J. \& Newhouse, J. P. (Eds.) Handbook of Health Economics. Amsterdam, Elsevier.

Wagstaff, A. \& Vandoorslaer, E. (1992) Equity in the Finance of Health-Care - Some International Comparisons. Journal of Health Economics, 11, 361-387.

Van Doorslaer, E., Wagstaff, A. \& Rutten, F. (Eds.) (1993) Equity in the Finance and Delivery of Health Care: an International Perspective, Oxford, Oxford University Press. 
Van Doorslaer, E., Wagstaff, A., Van Der Burg, H., Christiansen, T., De Graeve, D., Duchesne, I., Gerdtham, U. G., Gerfin, M., Geurts, J., Gross, L., Hakkinen, U., John, J., Klavus, J., Leu, R. E., Nolan, B., O'donnell, O., Propper, C., Puffer, F., Schellhorn, M., Sundberg, G. \& Winkelhake, O. (2000) Equity in the Delivery of Health Care in Europe and the US. Journal of Health Economics, 19, 553-583.

Yong, P. F., Milner, P. C., Payne, J. N., Lewis, P. A. \& Jennison, C. (2004) Inequalities in access to knee joint replacements for people in need. Annals of the Rheumatic Diseases, 63, 1483-9. 
Table III Multiple regression model with relative values of waiting times $\dagger$

\begin{tabular}{|c|c|c|c|c|c|c|c|c|c|c|}
\hline & Vascular & Orthopedics & & Gynecology & & Urology & Ophthalmology & & General Surgery & \\
\hline Gender & & & ** & NA & & NA & & & & \\
\hline Women & $1.12(0.84-1.48)$ & $0.83(0.73-0.94)$ & $* *$ & NA & & NA & $0.99(0.92-1.05)$ & & $1.00(0.85-1.18)$ & \\
\hline Men & 1.00 (REF) & 1.00 (REF) & & NA & & NA & 1.00 (REF) & & 1.00 (REF) & \\
\hline Age group & & & * & & & & & $*$ & & * \\
\hline $18-39$ & $0.49(0.20-1.17)$ & $0.95(0.73-1.24)$ & & $1.08(0.68-1.72)$ & & $0.81(0.34-1.90)$ & $0.75(0.54-1.05)$ & & $0.91(0.69-1.21)$ & \\
\hline $40-69$ & $1.09(0.81-1.48)$ & $1.18(1.02-1.36)$ & * & $0.98(0.78-1.23)$ & & $0.83(0.66-1.04)$ & $0.89(0.82-0.97)$ & ** & $1.19(0.94-1.51)$ & \\
\hline $70-$ & 1.00 (REF) & 1.00 (REF) & & 1.00 (REF) & & 1.00 (REF) & 1.00 (REF) & & 1.00 (REF) & \\
\hline Income group & & & $*$ & & & & & & & * \\
\hline Lowest & $1.06(0.73-1.54)$ & $1.27(1.07-1.49)$ & $* *$ & $0.86(0.67-1.10)$ & & $1.25(0.89-1.77)$ & $1.02(0.93-1.12)$ & & $1.34(1.06-1.68)$ & * \\
\hline Middle & $1.07(0.81-1.43)$ & $1.19(1.04-1.37)$ & * & $0.92(0.74-1.16)$ & & $0.91(0.74-1.11)$ & $0.98(0.90-1.06)$ & & $1.10(0.90-1.33)$ & \\
\hline Highest & 1.00 (REF) & 1.00 (REF) & & 1.00 (REF) & & 1.00 (REF) & 1.00 (REF) & & 1.00 (REF) & \\
\hline Ethnicity $¥$ & & & & & ** & & & & & \\
\hline Foreign & $1.24(0.85-1.8)$ & $1.10(0.90-1.34)$ & & $0.59(0.45-0.77)$ & ** & $1.18(0.81-1.72)$ & $1.07(0.96-1.18)$ & & $1.05(0.86-1.29)$ & \\
\hline Swedish & 1.00 (REF) & 1.00 (REF) & & 1.00 (REF) & & 1.00 (REF) & 1.00 (REF) & & 1.00 (REF) & \\
\hline Workforce activity & & & & & & & & ** & & \\
\hline No & $1.28(0.92-1.79)$ & $0.96(0.84-1.11)$ & & $1.09(0.90-1.33)$ & & $1.22(0.93-1.61)$ & $1.24(1.11-1.40)$ & ** & $0.98(0.83-1.15)$ & \\
\hline Yes & 1.00 (REF) & 1.00 (REF) & & 1.00 (REF) & & 1.00 (REF) & 1.00 (REF) & & 1.00 (REF) & \\
\hline
\end{tabular}

${ }^{\dagger}$ Adjusted for elective procedures

$*=$ sig. level 0.05
$* *=$ sig. level 0.0 